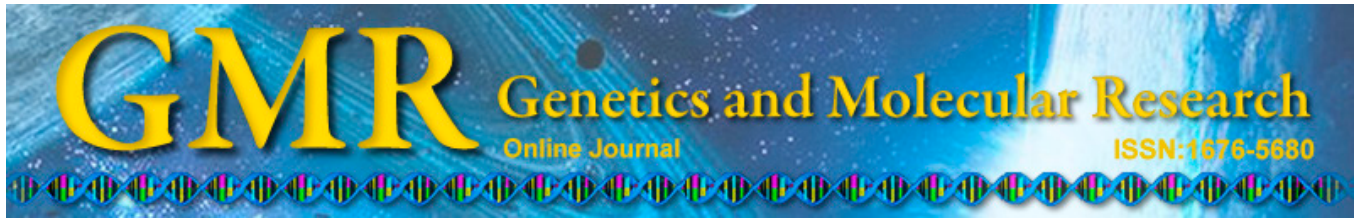

\title{
Feasibility of comfortable and secure intubation achieved with the Disposcope endoscope or Macintosh laryngoscope for patients in whom glottis viewing is difficult
}

\author{
X.-H. Li ${ }^{1}$, Z. Sun ${ }^{2}$ and L.-L. He ${ }^{3}$ \\ ${ }^{1}$ Department of Anesthesia, Weifang Medical University, Weifang, China \\ ${ }^{2}$ Department of Pathology, The Affiliated Hospital of Weifang Medical University, \\ Weifang, China \\ ${ }^{3}$ Department of Pain, Xuanwu Hospital, Capital Medical University, Beijing, \\ China
}

Corresponding author: X.-H. Li

E-mail: xiuhualicn@163.com

Genet. Mol. Res. 14 (2): 3694-3701 (2015)

Received July 1, 2014

Accepted October 28, 2014

Published April 17, 2015

DOI http://dx.doi.org/10.4238/2015.April.17.19

\begin{abstract}
We aimed to study the feasibility of a comfortable and secure intubation achieved with the Disposcope endoscope or Macintosh laryngoscope when glottis viewing is difficult. Forty adults scheduled for elective surgery under general anesthesia, in whom glottis viewing was difficult with the Macintosh laryngoscope (classified as CormackLehane Grade III or IV), were randomized into 2 groups $(\mathrm{N}=20$ each): Disposcope endoscope (Group D) and Macintosh laryngoscope (Group M). We recorded the successful glottis viewing rate; intubation time; successful intubation rate; incidence of systolic blood pressure (SBP) $\geq 140 \mathrm{mmHg}$ and heart rate (HR) $\geq 90 \mathrm{bpm}$ from the beginning of intubation to $5 \mathrm{~min}$ after intubation; and postoperative sore throat and hoarseness. Successful glottis viewing rate and successful first intubation rate were higher in Group D than in Group $\mathrm{M}(\mathrm{P}<0.05)$;
\end{abstract}


the number of intubations taking $>3$ min and with $\mathrm{SBP} \geq 140 \mathrm{mmHg}$ and HR $\geq 90 \mathrm{bpm}$ were less in Group $\mathrm{D}(\mathrm{P}<0.05)$. The visual analogue scale of postoperative sore throat 1 day after extubation was higher in Group M than in Group D $(\mathrm{P}<0.05)$. No significant differences were found in other indices $(\mathrm{P}>0.05)$. Better stability of hemodynamics, less intubation time, higher successful first intubation rate, and fewer incidences of postoperative sore throat were achieved in Group D than in Group M. Thus, comfortable and secure intubation can be achieved using the Disposcope endoscope in patients in whom glottis viewing is difficult.

Key words: Disposcope endoscope; Macintosh laryngoscope; Glottis; Secure intubation; Difficult airway

\section{INTRODUCTION}

A difficult airway signifies that a conventionally trained anesthesiologist experiences difficulty with face mask ventilation, tracheal intubation, or both (American Society of Anesthesiologists Task Force on Management of the Difficult Airway, 2003). For any patients undergoing general anesthesia, the assessment for a difficult airway is important to ensure that the anesthesiologist will be able to secure the operation. A difficult airway is often seen during endotracheal intubation in the setting of obesity, short neck, epiglottic cysts, burn injury, small jaw, or limited cervical movement (Saha et al., 1998; Sonny et al., 2011). Patients with difficult airways are often classified as Cormack-Lehane Grade III-IV, signifying difficult viewing of the glottis (Yildiz et al., 2005).

The Macintosh laryngoscope, a traditional device, is still used by many skilled operators in some hospitals for patients with difficult airways. When it is used for revealing the glottis, the triaxial-mouth, pharynx, and larynx must be in one line as much as possible, which can potentially increase the complications of endotracheal intubation (Kitsera et al., 1971; Collins et al., 2004). In general anesthesia, intubation with the Macintosh laryngoscope for patients whose glottis is difficult to view is challenging and frequently results in severe injury (Butler and Clyne, 2003). The operators often need to use violent force to pull the laryngoscope and must repeatedly perform a blind endotracheal intubation with a guided core, which can lead to severe stress responses in patients (high risk for patients with cardiac and brain diseases), mouth or throat mucous membrane bleeding, edema, swallowing pain, hoarseness, and even hypoxia (Taylor et al., 2013). The risks of endotracheal intubation with the Macintosh laryngoscope are high even when the procedure is performed by skilled medical personnel (Andersen et al., 2011).

The technique of endotracheal intubation is in need of modification, and advanced viewing devices have emerged to meet the need. The Disposcope endoscope (Hsinchuang, Taiwan) is an indirect viewing device that has the characteristics of both firmness and good plasticity and can avoid the violent pulling of the Macintosh laryngoscope when facing patients in whom glottis viewing is difficult (Park et al., 2013). It can achieve visualization of intubation (via glottis exposure on-screen) with few complications and a high success rate (Nouruzi-Sedeh et al., 2009). The Disposcope allows medical personnel to see the glottis easily; it requires less strength than the Macintosh laryngoscope, and its use can be grasped in short-term training (Paolini et al., 2013). 
Ideal anesthesia has four conditions: unconsciousness, absence of pain, muscle relaxation, and elimination of bad reflections. These conditions are also important for comfortable anesthesia. The emergence of comfortable anesthesia highlights the progress in anesthesia quality (Migneault et al., 2004). For endotracheal intubation, however, current interest focuses on the feasibility and efficacy of viewed endoscopic intubation compared with that of the direct laryngoscope, whereas research on comfortable intubation is rare (O'Leary et al., 2008; Sakles et al., 2012; Langley and Mar Fan, 2014). The proposed new concept of "comfortable anesthesia" includes the requirement of safe intubation. It is important for medical personnel and patients to realize both comfortable and safe intubation to reduce or avoid adverse reactions related to endotracheal intubation, such as hypertension, tachycardia, hypoxia, and airway injury (Maassen et al., 2009; Biro, 2011; Rosenstock et al., 2012). The aim of this study was to observe the comfort and safety of intubation in patients in whom the glottis was viewed with difficulty during intubation, comparing the Disposcope endoscope with the Macintosh laryngoscope.

\section{MATERIAL AND METHODS}

\section{Patient selection}

The study was performed between May 1, 2012 and June 30, 2013. It was approved by the Affiliated Hospital of Weifang Medical College Ethics Committee, and all patients gave informed consent. All the patients were scheduled to undergo elective surgery under general anesthesia with endotracheal intubation: 40 patients, with 22 males and 18 females, aged 31 to 67 years. Inclusion criteria were classification by Macintosh laryngoscope as CormackLehane Grade III or IV, and no asthma, allergies or history of opioid abuse. Using a randomnumber table, patients were divided into two groups $(\mathrm{N}=20$ each): Disposcope endoscope (Group D) and Macintosh laryngoscope (Group M).

\section{Anesthesia protocol}

Atropine $0.5 \mathrm{mg}$ and phenobarbital $0.1 \mathrm{~g}$ were administered by intramuscular injection $30 \mathrm{~min}$ before anesthesia induction. After the patient entered the operating room, an intravenous infusion of sodium lactate Ringer's solution at $10 \mathrm{~mL} \cdot \mathrm{kg}^{-1} \cdot \mathrm{h}^{-1}$ was started. Routine monitoring of blood pressure, heart rate (HR) and blood oxygen saturation $\left(\mathrm{SpO}_{2}\right)$ was performed. After an oxygen mask was in place for $3 \mathrm{~min}$, an intravenous injection of sufentanil $0.4 \mu \mathrm{g} / \mathrm{kg}$, propofol $2.5 \mathrm{mg} / \mathrm{kg}$, and rocuronium $0.8 \mathrm{mg} / \mathrm{kg}$ was administered, and then consciousness was lost. The TOF-Watch SX accelerometer (Organon Company, the Netherlands) with 4 clusters to stimulate the ulnar nerve was used to monitor adductor thumb twitching (stimulation parameters: current intensity $50 \mathrm{~mA}$, pulse width $0.2 \mathrm{~ms}$, frequency $2 \mathrm{~Hz}$ ). After successful endotracheal intubation and establishment of mechanical ventilation with tidal volume $=8 \mathrm{~mL} / \mathrm{kg}$, respiratory frequency $=12 \mathrm{bpm}$, and inspiratory-to-expiratory ratio $=1: 2$, the intraoperative sevoflurane concentration was adjusted according to the patient's condition. Intermittent intravenous sufentanil $0.2 \mu \mathrm{g} / \mathrm{kg}$ and rocuronium $0.4 \mathrm{mg} / \mathrm{kg}$ were administered as required throughout the surgery. At $10 \mathrm{~min}$ before the end of surgery, intravenous dezocine 5 $\mathrm{mg}$ was given. Intravenous analgesia pumps were not used. 


\section{Cormack-Lehane grading standards}

Glottis visualization was classified according to Cormack-Lehane grading standards as follows: Grade I - glottis is fully visible; Grade II - only the second half of the glottis and arytenoid cartilage is visible; Grade III - only the epiglottis is visible; Grade IV - neither the glottis nor epiglottis is visible. Patients with Cormack-Lehane Grade I or II were identified directly under the Macintosh laryngoscope, and patients with Grade III or IV were enrolled in the study.

\section{Procedure}

The Macintosh laryngoscope (Timesco Corporation, UK) was gently pulled upward to reveal the glottis for Cormack-Lehane grading. In Group M, the Macintosh laryngoscope was lifted further, with an intensity from gentle to hard. When the glottis opening revealed the border, the cricoid cartilage should be pressed, a "hook-like" plastic sleeve was placed. If the Cormack-Lehane classification changed from III/IV to II/I with force and pressing the cricoid cartilage, endotracheal intubation would be directly done. If the Cormack-Lehane Grade III/ IV was no improvement, the blind searching method was used: the laryngoscope was moved close to the rear wall of the epiglottis or close to the rear wall of the glottis slowly from left to right, looking for the glottis for endotracheal intubation. In Group M, the successful criteria for exposing the glottis was the Cormack-Lehane classification $<$ Grade III; in Group D, the successful criteria was the glottis visualization with the Disposcope endoscope, which entered along the middle of the tongue. Disposcope endoscopic intubation preparation: the tip of the endoscope was placed 6-7 cm from the front of the endotracheal tube, at a $90^{\circ}$ angle, to attain an appropriate visualization without revealing the endotracheal catheter tip. If the intubation time was more than $180 \mathrm{~s}$ or $\mathrm{SpO}_{2} \leq 95 \%$ during the intubation, the second intubation was done with the mask ventilation. If the second intubation was unsuccessful, the procedure was diverted to other guiding tools.

\section{Recording indices}

1) Case of the revealed glottis. 2) Intubation time (Group $M$, from insertion of Macintosh laryngoscope to catheter placement; Group D, from insertion of Disposcope endoscope to placement of conduit. Regardless of the number of attempts required for successful intubation, time was measured from the first mirror/endoscopic catheter placement to the last successful placement; if the second intubation was successful, the time was measured from insertion of the first laryngoscope/endoscope to when the catheter was inserted on the second attempt). 3) Intubation success (first attempt successful, second attempt successful, or diverted to other intubation methods). 4) Number of cases with $\mathrm{SBP} \geq 140 \mathrm{mmHg}$ and $\mathrm{HR} \geq 90 \mathrm{bpm}$ after 5 min of endotracheal intubation. 5) Catheter placement time (endotracheal intubation to extubation). 6) Perioperative dosage of sufentanil. 7) Oral/throat mucous membrane bleeding (Macintosh laryngoscope in Group M, or Disposcope endoscope in Group D is not stained with blood after intubation). Visual analogue scale (VAS) assessment of swallowing pain $(0=$ painless; 10 unbearable pain $)$ and hoarseness $(0=$ none; $1=$ mild; $2=$ moderate; $3=$ severe $)$ at 30 min, 1 day, 3 days after extubation. 


\section{Statistical analysis}

We used the GraphPad Prism 5.0 statistical software for statistical analysis. Normal distribution of measurement data is reported as means \pm standard deviation and skewed distribution of the measurement data to the median (interquartile range) as $[\mathrm{M}(\mathrm{Q})]$. A P value $<$ 0.05 was considered to be statistically significant.

\section{RESULTS}

Differences in gender, age, BMI, and Cormack-Lehane grade were not statistically significant between Group M and Group D (P > 0.05). Detailed information on patients is shown in Table 1.

Table 1. General characteristics of the two groups.

\begin{tabular}{lcccc}
\hline Group & Gender $(\mathrm{M} / \mathrm{F})$ & Age (years, means $\pm \mathrm{SD})$ & BMI $\left(\mathrm{kg} / \mathrm{m}^{2}\right.$, means $\left.\pm \mathrm{SD}\right)$ & Cormack-Lehane Grade $(\mathrm{III} / \mathrm{IV})$ \\
\hline $\mathrm{M}(\mathrm{N}=20)$ & $13 / 7$ & $45 \pm 11$ & $28 \pm 6$ & $20 / 0$ \\
$\mathrm{D}(\mathrm{N}=20)$ & $9 / 11$ & $42 \pm 13$ & $27 \pm 5$ & $19 / 1$ \\
\hline
\end{tabular}

In Group M, 3 patients failed intubation after 2 attempts with the Macintosh laryngoscope. They were then diverted to intubation with the GlideScope video laryngoscope, which was successful in all 3 cases (included in the study). In Group M, 3 patients failed intubation due to two times for the Macintosh laryngoscope intubation and then diverted GlideScope video laryngoscopes, which were successful (included in the study). In Group D, the success rate of intubation (once or twice) was 100\% with the Disposcope endoscope. The rates of successful glottis viewing and first successful intubation were higher in Group D than in Group $\mathrm{M}(\mathrm{P}<0.05)$ after the pulling force increased from gentle to hard exertion. Compared with Group M, the number of intubations taking longer than 3 min or resulting in $\mathrm{SBP} \geq 140 \mathrm{mmHg}$ and HR $\geq 90 \mathrm{bpm}$ were fewer in Group D $(\mathrm{P}<0.05)$. No significant difference was found in intubation placement time, perioperative sufentanil dosage, or swallowing pain 30 min after extubation between the two groups (Table 2).

Table 2. Comparison of glottis exposure, intubation time, successful rate of intubation, hemodynamic changes from intubation to intubation after $5 \mathrm{~min}$, catheter placement time, and perioperative use of sufentanil $(\mathrm{N}=20)$.

\begin{tabular}{|c|c|c|c|c|c|c|c|c|c|c|c|c|}
\hline \multirow[t]{2}{*}{ Group } & \multirow{2}{*}{$\begin{array}{c}\text { Successful } \\
\text { glottis exposure } \\
{[\mathrm{N}(\%)]}\end{array}$} & \multicolumn{4}{|c|}{ Intubation time $[\mathrm{N}(\%)]$} & \multicolumn{3}{|c|}{$\begin{array}{l}\text { Successful rate for } \\
\text { intubation }[\mathrm{N}(\%)]\end{array}$} & \multirow{2}{*}{$\begin{array}{c}\mathrm{SBP} \geq 140 \\
\mathrm{mmHg} \\
{[\mathrm{N}(\%)]}\end{array}$} & \multirow[t]{2}{*}{$\begin{array}{c}\mathrm{HR} \geq 90 \mathrm{bpm} \\
{[\mathrm{N}(\%)]}\end{array}$} & \multirow{2}{*}{$\begin{array}{c}\text { Catheter } \\
\text { placement } \\
\text { time }(\min \pm S D)\end{array}$} & \multirow{2}{*}{$\begin{array}{c}\text { Use of } \\
\text { sufentanil } \\
(\mu \mathrm{g} \pm \mathrm{SD})\end{array}$} \\
\hline & & $\leq 1 \mathrm{~min}$ & $\leq 2 \mathrm{~min}$ & $\leq 3 \mathrm{~min}$ & $>3 \mathrm{~min}$ & Once & Twice & Other & & & & \\
\hline M & $8(40)$ & $10(50)$ & $3(15)$ & $1(5)$ & $6(30)$ & $10(50)$ & $7(35)$ & $3(15)$ & $10(50)$ & $12(60)$ & $102 \pm 35$ & $38 \pm 5$ \\
\hline $\mathrm{D}$ & $20(100)^{*}$ & $14(70)$ & $5(25)$ & $1(5)$ & $0(0)^{*}$ & $17(85)^{*}$ & $3(15)$ & $0(0)$ & $1(5)^{*}$ & $3(15)^{*}$ & $115 \pm 27$ & $36 \pm 7$ \\
\hline
\end{tabular}

The VAS of postoperative sore throat at 1 day and 3 days after extubation was higher in Group M than in Group D $(\mathrm{P}<0.05)$. The VAS of postoperative sore throat at 30 min after extubation was not significantly different between the two groups $(\mathrm{P}>0.05)$. For Group $\mathrm{M}$, the VAS of sore throat at 1 day was higher than at $30 \mathrm{~min}$ and 3 days after extubation $(\mathrm{P}<$ 
0.05); For Group D, the VAS of sore throat at 30 min was higher than at 1 day and 3 days after extubation $(\mathrm{P}<0.05$; Table 3$)$.

Table 3. VAS of swallowing pain between the two groups $[\mathrm{M}(\mathrm{Q})]$ at $30 \mathrm{~min}, 1$ day, and 3 days after extubation.

\begin{tabular}{llcc}
\hline Group & \multicolumn{2}{c}{ Time after extubation } \\
\cline { 2 - 4 } & $30 \mathrm{~min}$ & 1 day & 3 days \\
\hline $\mathrm{M}(\mathrm{N}=20)$ & $1(1-2)$ & $3(1-5)^{\mathrm{a}}$ & $1(0-1)^{\mathrm{b}}$ \\
$\mathrm{D}(\mathrm{N}=20)$ & $1(0-1)$ & $0(0-1)^{\mathrm{ac}}$ & $0(0-0)^{\mathrm{ac}}$ \\
\hline
\end{tabular}

${ }^{\mathrm{a}}$ Compared with 30 min after extubation, $\mathrm{P}<0.05$. ${ }^{\mathrm{b}}$ Compared with 1 day after extubation, $\mathrm{P}<0.05$. ${ }^{\mathrm{c} C o m p a r e d}$ with group $\mathrm{M}, \mathrm{P}<0.05$. VAS $=$ visual analogue scale $(0=$ no pain; $10=$ unbearable pain $)$.

No significant differences were found in the degree of hoarseness at $30 \mathrm{~min}, 1$ day, and 3 days after extubation between Group $\mathrm{M}$ and Group D ( $\mathrm{P}>0.05)$. Compared with $30 \mathrm{~min}$ after extubation, the degree of hoarseness decreased at 1 day and 3 days after extubation in both groups $(\mathrm{P}<0.05$; Table 4$)$.

Table 4. Comparison of the degree of hoarseness between the two groups $[\mathrm{M}(\mathrm{Q})]$ at 30 min, 1 day, and 3 days
after extubation.
\begin{tabular}{llcc}
\hline Group & Time after extubation \\
\cline { 2 - 4 } & 30 min & 1 day & 3 days \\
\hline $\mathrm{M}(\mathrm{N}=20)$ & $1(1-2)$ & $0(0-1)$ & $0(0-0)$ \\
$\mathrm{D}(\mathrm{N}=20)$ & $1(1-1)$ & $0(0-0)$ & $0(0-0)$ \\
\hline
\end{tabular}

Hoarseness $(0=$ none; $1=$ mild; $2=$ moderate; $3=$ severe $)$.

\section{DISCUSSION}

The Disposcope endoscope, a new video laryngoscope, is an effective device for intubation (Park et al., 2013). It is often used to solve the problem of the difficult airway, yielding a high rate of successful intubation and few complications (Pott and Murray, 2008). Our study showed that the Disposcope endoscope could truly achieve a comfortable and safe endotracheal intubation for patients in whom glottis viewing was difficult.

During the procedure, to avoid damaging the throat mucosa with violent pulling of the laryngoscope and adversely affecting the final outcome, the operator only pulled the Macintosh laryngoscope gently. Patients were selected by rating the visualization of the glottis according to the Cormack-Lehane classification. The study showed no significant difference between the Disposcope endoscope group and the Macintosh laryngoscope in the VAS scores of swallowing pain at $30 \mathrm{~min}$ after extubation. However, at 1 day after extubation, the VAS score of swallowing pain in Group M was significantly higher than that in Group D, whereas at 3 days after extubation, the VAS of swallowing pain in Group M decreased but was still higher than that in Group D. The degree of hoarseness at $30 \mathrm{~min}, 1$ day, and 3 days after extubation was similar in both groups.

The results of this study showed that in all patients who underwent Disposcope endoscopic tracheal intubation, the glottis was successfully visualized without violent pulling of the laryngoscope while, at the same time, successfully avoiding blind intubation. The success 
rate of intubation on the first attempt was significantly better in Group D as compared with that of Group M (85 vs 50\%). In Group M, when the intensity of pulling the Macintosh laryngoscope was changed from gentle to hard, the Cormack-Lehane classification in 8 patients improved from Grade III to Grade II. However, in the remaining patients, the glottis was not visible. Two attempts to achieve a successful intubation occurred significantly more often in Group M than in Group D, indicating that mechanical injuries to the patients around the glottal and throat mucosa were increased. Moreover, significantly more patients in Group M than in Group D had intubation times $>3$ min, which suggests increased mechanical damage to the throat and supraglottic mucosa. Thus, the effectiveness of the Disposcope endoscope could enhance safety during airway management (Nouruzi-Sedeh et al., 2009; Paolini et al., 2013).

The fact that no difference was seen between the two groups in the VAS of swallowing pain at $30 \mathrm{~min}$ after extubation ( $1 v s$ 1) might be associated with the perioperative use of sufentanil and the administration of dezocine before the end of surgery. At 1 day after extubation, the VAS of swallowing pain was significantly higher in Group M than in Group D ( $3 v s$ 0 ). This might have occurred for 3 reasons: pulling the Macintosh laryngoscope with force; the increased number of intubations requiring two attempts; and the extended time required for positioning the Macintosh laryngoscope and intubation probe (blind exploration). At 3 days after extubation, 2 patients in Group M reported VAS $=3$ for swallowing pain, and in Group $\mathrm{D}$, all patients reported VAS $=0$ for swallowing pain; however, the difference between the two groups was not statistically significant. At 30 min after extubation, both groups of patients had a mild degree of hoarseness, and at 1 and 3 days after extubation, the degree of hoarseness was significantly improved in the two groups. Thus, application of the Disposcope endoscope could enhance patient's comfort after extubation (Paolini et al., 2013).

In summary, the Disposcope endoscope was used for patients in whom glottis viewing was difficult. Using the Disposcope could avoid violent pulling of the Macintosh laryngoscope, reduce intubation (blind probe) time, improve the success rate of one-time intubation, and effectively decrease the postoperative incidence of patients with swallowing pain. In this way, comfortable and safe endotracheal intubation could be achieved, ensuring safe intubation as an important part of the clinical comfort of anesthesia.

\section{REFERENCES}

American Society of Anesthesiologists Task Force on Management of the Difficult Airway (2003). Practice guidelines for management of the difficult airway: an updated report by the American Society of Anesthesiologists Task Force on Management of the Difficult Airway. Anesthesiology 98: 1269-1277.

Andersen LH, Rovsing L and Olsen KS (2011). GlideScope videolaryngoscope vs Macintosh direct laryngoscope for intubation of morbidly obese patients: a randomized trial. Acta Anaesthesiol. Scand. 55: 1090-1097.

Biro P (2011). The evolutionary reason for the need to secure the airway in anesthesiology. Isr. Med. Assoc. J. 13: 5-8.

Butler KH and Clyne B (2003). Management of the difficult airway: alternative airway techniques and adjuncts. Emerg. Med. Clin. North. Am. 21: 259-289.

Collins JS, Lemmens HJ, Brodsky JB, Brock-Utne JG, et al. (2004). Laryngoscopy and morbid obesity: a comparison of the "sniff" and "ramped" positions. Obes. Surg. 14: 1171-1175.

Kitsera AE, Borisov AA and Kruk MV (1971). Direct epipharyngoscopy using the Macintosh intubation laryngoscope. Zh. Ushn. Nos. Gorl. Bolezn. 31: 121-122.

Langley A and Mar Fan G (2014). Comparison of the glidescope ${ }^{\circledast}$, flexible fibreoptic intubating bronchoscope, iPhone modified bronchoscope, and the Macintosh laryngoscope in normal and difficult airways: a manikin study. BMC Anesthesiol. 14: 10.

Maassen R, Lee R, Hermans B, Marcus M, et al. (2009). A comparison of three videolaryngoscopes: the Macintosh laryngoscope blade reduces, but does not replace, routine stylet use for intubation in morbidly obese patients. Anesth. 
Analg. 109: 1560-1565.

Migneault B, Girard F, Albert C, Chouinard P, et al. (2004). The effect of music on the neurohormonal stress response to surgery under general anesthesia. Anesth. Analg. 98: 527-532.

Nouruzi-Sedeh P, Schumann M and Groeben H (2009). Laryngoscopy via Macintosh blade versus GlideScope: success rate and time for endotracheal intubation in untrained medical personnel. Anesthesiology 100: 32-37.

O'Leary AM, Sandison MR, Myneni N, Cirilla DJ, et al. (2008). Preliminary evaluation of a novel videolaryngoscope, the McGrath series 5, in the management of difficult and challenging endotracheal intubation. J. Clin. Anesth. 20: 320-321.

Paolini JB, Donati F and Drolet P (2013). Review article: video-laryngoscopy: another tool for difficult intubation or a new paradigm in airway management? Can. J. Anaesth. 60: 184-191.

Park SO, Shin DH, Lee KR, Hong DY, et al. (2013). Efficacy of the Disposcope endoscope, a new video laryngoscope, for endotracheal intubation in patients with cervical spine immobilisation by semirigid neck collar: comparison with the Macintosh laryngoscope using a simulation study on a manikin. Emerg. Med. J. 30: 270-274.

Pott LM and Murray WB (2008). Review of video laryngoscopy and rigid fiberoptic laryngoscopy. Curr. Opin. Anaesthesiol. 21: 750-758.

Rosenstock CV, Thøgersen B, Afshari A, Christensen AL, et al. (2012). Awake fiberoptic or awake video laryngoscopic tracheal intubation in patients with anticipated difficult airway management: a randomized clinical trial. Anesthesiology 116: 1210-1216.

Saha AK, Higgins M, Walker G, Badr A, et al. (1998). Comparison of awake endotracheal intubation in patients with cervical spine disease: the lighted intubating stylet versus the fiberoptic bronchoscope. Anesth. Analg. 87: 477-479.

Sakles JC, Mosier JM, Chiu S and Keim SM (2012). Tracheal intubation in the emergency department: a comparison of GlideScope ${ }^{\circledast}$ video laryngoscopy to direct laryngoscopy in 822 intubations. J. Emerg. Med. 42: 400-405.

Sonny A, Nagaraj G and Ramachandran R (2011). Asymptomatic epiglottic cyst: a rare cause of unanticipated difficult intubation. Middle East J. Anesthesiol. 21: 119-120.

Taylor AM, Peck M, Launcelott S, Hung OR, et al. (2013). The McGrath ${ }^{\circledR}$ Series 5 videolaryngoscope $v s$ the Macintosh laryngoscope: a randomised, controlled trial in patients with a simulated difficult airway. Anaesthesia 68: 142-147.

Yildiz TS, Solak M and Toker K (2005). The incidence and risk factors of difficult mask ventilation. J. Anesth. 19: 7-11. 